\title{
$\$$ Research Square \\ Planetary emittance and feedback parameters through varying climates in basic modelling
}

\section{Thomas Anderl ( $\square$ thomas.anderl@hotmail.de) \\ BHU Research}

\section{Research Article}

Keywords: climate modelling, planetary emittance, faint young Sun paradox

Posted Date: July 9th, 2021

DOI: https://doi.org/10.21203/rs.3.rs-692319/v1

License: (c) (i) This work is licensed under a Creative Commons Attribution 4.0 International License. Read Full License 


\section{Abstract}

In search for reproducibility of the results from sophisticated scientific research, the present work focuses on the planetary (longwave) emittance variabilities. A simple model appears applicable through the entire range from very cold to extremely warm climates and for different climate driving forces, i.e. solar luminosity variation and $\mathrm{CO}_{2}$ concentration change. The results interrelate effects from lapse rate, water vapor, $\mathrm{CO}_{2}$, and clouds for equilibrium climate states. Feedback parameters are analysed for the emittance decomposition into the atmospheric window, clouds, and the cloud-free atmosphere. A view is devoted to the faint young Sun problem.

\section{Introduction}

Just as the Sun warms Earth, Earth is cooled by longwave radiation escaping into space. This planetary emittance is strongly interrelated with the vertical temperature profile of the atmosphere which in turn is a result of rather complex balancing mechanisms. Big progress has been achieved incorporating the natural complexity into simulation programs - at the disadvantage that specific understanding is difficult to be extracted. On the other hand, theoretical framework of lower complexity can be too coarse for certain depths of comprehension.

In search for reproducibility of the sophisticated research results, the present studies attempt to sort the importance of phenomena such as: feedbacks from water vapor, lapse rate, and clouds; change of emittance altitude and temperature with surface temperature; cooling of the stratosphere. These topics appear scarcely described in their relation to a general understanding of the natural climate variabilities.

For assessment by simple means, the present studies make use of observational results where bottom-up computation appears too complex, and combine these with few fundamental principles.

\section{Co2 Contribution To The Atmospheric Longwave Emittance}

Throughout the present work, total planetary emittance is regarded composed of radiation from the surface through the atmospheric window, radiation from clouds, and radiation from the (cloud-free) atmosphere.

From measurements as of Figure 1 [1], planetary emittance from the $\mathrm{CO}_{2}$ absorption band at wavenumber $670 \mathrm{~cm}^{-1}$ (wavelength $15 \mu \mathrm{m}$ ) corresponds to a blackbody temperature of about $217 \mathrm{~K}$, i.e. $6 \mathrm{~W} / \mathrm{m}^{2} / \mu \mathrm{m}$ according to the Planck function, the emittance width revealed as approximately $3 \mu \mathrm{m}$. Thus, $\mathrm{CO}_{2}$ radiates into space in the order of $18 \mathrm{~W} / \mathrm{m}^{2}$ - nearly independent of the surface temperature from comparison of the three climate cases in Figure 1. This compares to $169 \mathrm{~W} / \mathrm{m}^{2}$ of total planetary emittance from the atmosphere (cf. [2]), i.e. $10 \%$ as rule-of-thumb. The other $90 \%$ of planetary emittance are understood as dominated by water vapor.

It is a simple, but certainly significant observation that $\mathrm{CO}_{2}$ contributes with $10 \%$ to Earth's cooling and $\mathrm{H}_{2} \mathrm{O}$ at nearly 9 times, and that the emittance from $\mathrm{CO}_{2}$ is almost independent of the surface temperature. 


\section{Three-component Planetary Emittance And Feedback Parameters}

As mentioned, total planetary emittance is regarded composed of radiation from the surface through the atmospheric window, radiation from clouds, and radiation from the (cloud-free) atmosphere.

For a first-order estimate, radiation through the atmospheric window is approximated to proportionally scale with the blackbody surface radiation. The present value is taken as $40 \mathrm{~W} / \mathrm{m}^{2}$ (cf. [2]). Thus, the window emittance is estimated to increase by about $0.6 \mathrm{~W} / \mathrm{m}^{2} / \mathrm{K}$ for a surface temperature rise of $1 \mathrm{~K}$. This is equivalent to a feedback parameter of $-0.6 \mathrm{~W} / \mathrm{m}^{2} / \mathrm{K}$, the minus sign since the emittance increase represents a cooling contribution counteracting the associated temperature increase. (Throughout the present work, the feedback parameter is used to indicate the variations of longwave emittance to space in dependence on the surface temperature.)

From previous sophisticated research, the net effect of clouds was assessed with a feedback parameter of $0.7 \mathrm{~W} / \mathrm{m}^{2} / \mathrm{K}$, recently revised to $0.3 \mathrm{~W} / \mathrm{m}^{2} / \mathrm{K}[3]$.

Now, the specific case is considered of varying surface temperature upon a $\mathrm{CO}_{2}$ concentration change and unaltered absorbed insolation. In equilibrium states, as e.g. on average approximately experienced during the Eocene [3], longwave emittance must remain constant since absorbed energy is unchanged. Hence, the feedback parameter of the total planetary emittance is required to be zero (no emittance change upon surface temperature change). With the above values for emittance through the atmospheric window and from clouds, the feedback parameter for longwave radiation from the (cloud-free) atmosphere is required to be either -0.1 or $+0.3 \mathrm{~W} / \mathrm{m}^{2} /{ }^{\circ} \mathrm{C}$ for the two cloud feedback values, respectively.

This stimulates a deeper look.

\section{Planetary Emittance In A Simple Model}

With this aim, a simplified model has been applied to estimate the longwave emittance from the atmosphere.

\subsection{Model description}

A summary of the model is depicted in Figure 2. The atmosphere is divided into $1 \mathrm{~km}$-altitude steps. Starting point is an observation-based vertical temperature profile, changing with surface temperature according to the blue lines in Figure 2 (shown for two extreme temperature cases). The stratospheric temperature can be adjusted manually. The lapse rate is $6.5 \mathrm{~K} / \mathrm{km}$ at $287 \mathrm{~K}$ (global annual mean) surface temperature and variable with surface temperature, the studies covering 0 to $0.08(\mathrm{~K} / \mathrm{km}) / \mathrm{K}$.

The relative particle densities are given by their mixing ratios multiplied with the general density gradient, the latter to reflect $1 / \mathrm{e}$-diminution per $8 \mathrm{~km}$ height. The $\mathrm{CO}_{2}$ mixing ratio is set constant at all altitudes (dotted green line in Figure 2). The $\mathrm{H}_{2} \mathrm{O}$ mixing ratio (i) follows the vertical pattern as depicted in Figure 2 (dashed orange line), (ii) is temperature dependent at the ground, 0.4 volume- $\%$ for $288 \mathrm{~K}$ - temperature 
dependency either linear by $9.2 \% / \mathrm{K}$ (approximation revealed in [4] for the longwave absorption-totemperature relationship), or exponentially by $7 \% / \mathrm{K}$ (close to the Clausius-Clapeyron relation), or proportional to the saturation water vapor pressure (Clausius-Clapeyron relation); (iii) the vertical densities are scaled proportionally to the ground value.

Radiation occurs according to the blackbody at any location in the atmosphere and is proportional to the wavelength-related absorbing/emitting particle densities. The spectrum is divided into three regimes: the $\mathrm{CO}_{2}$ absorption band at $15 \mu \mathrm{m}$ and the adjacent wavelengths, represented by 7 and $21 \mu \mathrm{m}$, in the model solely related to $\mathrm{H}_{2} \mathrm{O}$. The wavelength regimes are treated separately. The wavelength span for each regime is determined to match the reported $169 \mathrm{~W} / \mathrm{m}^{2}$ of emittance at $289 \mathrm{~K}$ (cf. [2] with original references); in result, the wavelength spans are $3 \mu \mathrm{m}$ for the $15 \mu \mathrm{m}-\mathrm{CO}_{2}$-regime, 11.7 and $9 \mu \mathrm{m}$ for the regimes at 7 and $21 \mu \mathrm{m}$, respectively. To avoid a radiation bias dependent on surface temperature with the effect to synchronize model surface radiation with the (ideal) blackbody radiance, the wavelength spans vary with surface temperature by -0.009 and $0.005 \mu \mathrm{m} / \mathrm{K}$ for 7 and $21 \mu \mathrm{m}$, respectively.

For the transmissivity to space from a certain altitude, the attenuation of upward radiation is taken as inverse-exponential to the aggregated particle densities above the considered altitude divided by a density length. The latter is determined such that the spectral emittance matches the measurements of Figure 1: as mentioned earlier for $\mathrm{CO}_{2}$, the average emittance corresponds to an effective temperature of about $217 \mathrm{~K}$, thus to $6 \mathrm{~W} / \mathrm{m}^{2} / \mu \mathrm{m}$ for $15 \mu \mathrm{m}$ wavelength; for ' $\mathrm{H}_{2} \mathrm{O}$ ', the measurement for the Mediterranean climate is taken as reference, the average effective emittance temperature read from Figure 1 as $257 \mathrm{~K}$, thus with 7.6 $\mathrm{W} / \mathrm{m}^{2} / \mu \mathrm{m}$ for $7 \mu \mathrm{m}$ wavelength and $6.9 \mathrm{~W} / \mathrm{m}^{2} / \mu \mathrm{m}$ for $21 \mu \mathrm{m}$. From this, the density lengths are $7 \cdot 10^{-5} \mathrm{for}$ $\mathrm{CO}_{2}$ and $2 \cdot 10^{-4}$ for the ' $\mathrm{H}_{2} \mathrm{O}$ ' wavelengths. These values are assumed relating to a surface temperature of $288 \mathrm{~K}$.

Hence, Planck's spectral exitance (here denoted as $B_{z, \lambda}$, with the dependencies on altitude, $z$, and wavelength, $\lambda$ ) together with the vertical profiles of particle density and temperature determine the vertical transmittance distribution. Transmittance to space from a specific altitude is reflected into the prescribed temperature at the next higher altitude interval, effective relative to pre-industrial conditions. The atmospheric emittance to space is the sum of the transmittances from all altitude intervals and all wavelengths.

Total planetary longwave emittance is the sum of the emittances from the atmosphere (modelled as described), through the atmospheric window (approximated as described earlier), and from clouds. For the atmospheric window, a closer inspection has revealed that the chosen approximation is applicable for the studied conditions (details not shown). The emittance from clouds is scaled proportionally to the surface temperature by the feedback parameter, see the following notes on the considered values, with reference emittance of $30 \mathrm{~W} / \mathrm{m}^{2}$ at $289 \mathrm{~K}$ (cf. [2]).

The estimation scheme certainly represents a strong simplification of nature's complexity. Sensitivity studies have been performed by varying the temperature dependencies of $\mathrm{H}_{2} \mathrm{O}$ density and lapse rate as 
well as the feedback parameter for the net emittance effect from clouds. Furthermore, the analysis has covered a wide range of climate situations including extremes such as $278 \mathrm{~K}$ and $315 \mathrm{~K}$ of surface temperature. Two climate driving forces have been considered: $\mathrm{CO}_{2}$ or insolation determining the temperature variabilities, albedo changes from snow/ice taken into account at the lower temperatures. The subsequent presentation concentrates on the results revealed as robust, with the specific parameter base: scaling of the $\mathrm{H}_{2} \mathrm{O}$ concentration-temperature dependency by the saturation water vapor pressure, 0.05 $(\mathrm{K} / \mathrm{km}) / \mathrm{K}$ lapse rate temperature dependency, and $0.7 \mathrm{~W} / \mathrm{m}^{2} / \mathrm{K}$ cloud feedback. The latter agrees well with the $0.8 \mathrm{~W} / \mathrm{m}^{2} / \mathrm{K}$ inferred from the comparison between all-sky energy budget studies and clear-sky measurements ([2] with further reference). The considered albedo effects are, relative to $287 \mathrm{~K}$ surface temperature (minus/plus for cooling/warming effect): $-14,-3,+1,+2 \mathrm{~W} / \mathrm{m}^{2}$ for $278,284,291,>294 \mathrm{~K}$, respectively.

\subsection{Model results}

\subsection{1 $\mathrm{CO}_{2}$ driving temperature}

For the case of $\mathrm{CO}_{2}$ driving temperature, the observed $\mathrm{CO}_{2}$-temperature situations of the Eocene [4] are well reproduced by the simple model, also when extrapolated to 284 and $306 \mathrm{~K}$, corresponding to atmospheric $\mathrm{CO}_{2}$ concentrations between 176 and 3600 ppmv (see appendix Table 1 for details). Condition is that the stratospheric temperature is reduced relative to the prescribed profile between about $291 \mathrm{~K}$ and $300 \mathrm{~K}$ surface temperature, the reduction topping at $-29 \mathrm{~K}$. The pattern of the stratospheric cooling is expected to arise from $\mathrm{CO}_{2}$ radiation to space and ozone temperature dependencies.

Emittance altitude and temperature are found to change with surface temperature. For instance for the surface temperature rise from 284 to $306 \mathrm{~K}$, with the $\mathrm{CO}_{2}$ concentration rising from 176 to $3600 \mathrm{ppmv}$, peak

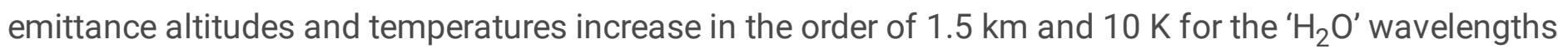
and by $25 \mathrm{~km}$ and $20 \mathrm{~K}$ for $\mathrm{CO}_{2}$, respectively.

From pre-industrial conditions ( $287 \mathrm{~K}$ surface temperature, $\left.276 \mathrm{ppmv} \mathrm{CO}_{2}\right)$ to very hot climates $(306 \mathrm{~K}$, $3600 \mathrm{ppmv}$ ), the atmospheric emittance varies in non-linear manner with surface temperature. For the regime of $\mathrm{CO}_{2}$-doubling from pre-industrial, the (clear-sky) atmosphere emittance increases by 0.36 $\mathrm{W} / \mathrm{m}^{2} / \mathrm{K}$, corresponding to the feedback parameter of $-0.36 \mathrm{~W} / \mathrm{m}^{2} / \mathrm{K}$.

\subsubsection{Temperature driving $\mathrm{CO}_{2}$}

For the case of absorbed insolation driving temperature, the $\mathrm{CO}_{2}$ concentration roughly follows surface temperature by $20 \mathrm{ppmv} / \mathrm{K}$ [4]. At low temperatures, the present consideration views albedo change as climate driver. At higher temperature with vanished glaciation, solar luminosity variation is taken as the dominant climate driver. In these cases for equilibrium states, longwave emittance must increase in line with absorbed energy. 
In result, the simple model can well reflect the conditions from 278 to $315 \mathrm{~K}$ if the stratosphere warms with solar luminosity rise (see appendix Table 2 for details). The warming is interpreted to originate from larger shortwave absorption as insolation increases.

The feedback parameters are revealed rather independent of the surface temperature above $284 \mathrm{~K}$ surface temperature, here listed together with insolation forcing per temperature change: $+1,+0.7,-0.6,-1.1 \mathrm{~W} / \mathrm{m}^{2} / \mathrm{K}$ for absorbed insolation, clouds, atmospheric window, atmosphere.

\subsubsection{Dealing with cloud feedback uncertainties}

The present model appears applicable for the entire range of cloud feedback parameters as reported from the sophisticated simulations (i.e. 0.7 and $0.3 \mathrm{~W} / \mathrm{m}^{2} / \mathrm{K}$, see above) when adapting the stratospheric temperature. Cloud feedback is considered as fit parameter in the present approach. The results appear soundest if the longwave radiation from clouds varies with surface temperature by $0.7 \mathrm{~W} / \mathrm{m}^{2} / \mathrm{K}$ (for preciseness, representing the compound effect related to clouds).

\subsubsection{Summary on atmospheric $\mathrm{CO}_{2}$ concentration doubling}

Using the Eocene as blueprint [4] for doubling of the atmospheric $\mathrm{CO}_{2}$ concentration, equilibrium is given at $287 \mathrm{~K}$ surface temperature for $276 \mathrm{ppmv} \mathrm{CO}_{2}$ concentration and at $291.7 \mathrm{~K}$ for $552 \mathrm{ppmv}$.

For the transition to the target state, the present scheme yields a feedback parameter for the atmospheric emittance of $-0.36 \mathrm{~W} / \mathrm{m}^{2} / \mathrm{K}$ (see above), dominated by $\mathrm{CO}_{2}\left(80 \%\right.$ ) with near-cancellation between the ' $\mathrm{H}_{2} \mathrm{O}$ ' wavelengths. The other feedback parameters are estimated to: absorbed insolation (from snow/ice albedo) +0.21 , clouds +0.7 , and atmospheric window $-0.55 \mathrm{~W} / \mathrm{m}^{2} / \mathrm{K}$.

\subsubsection{Earth during the faint young Sun}

Since a tool has come at hand to even look at very high temperatures and $\mathrm{CO}_{2}$ concentrations, it seems interesting to have a view on the faint young Sun problem, related to the period from the Early Archean to the Late Proterozoic, 4 to $1 \mathrm{Ga}$ before present (BP). The period is characterized by relatively low Sun luminosity, high Earth temperature, high atmospheric $\mathrm{CO}_{2}$ and low oxygen concentration, and the transition from mostly oceanic coverage to nearly the present continental emergence. Insolation at the top of the atmosphere was approximately 80 and $20 \mathrm{~W} / \mathrm{m}^{2}$ below the current level at 4 and $1 \mathrm{Ga} B$, respectively (cf. [1]). Temperatures and atmospheric composition are only known with high uncertainties. For the present analysis, the regarded values have exemplary character: A surface temperature of $306 \mathrm{~K}$ with atmospheric concentrations of 30,000 and 3,600 ppmv at 4 and $1 \mathrm{Ga} B P$, respectively.

It is expected that the low atmospheric oxygen concentration has effected a stratospheric cooling contribution due to reduced shortwave absorption. On the other hand, lower atmospheric shortwave absorption has entailed higher shortwave fraction being absorbed at the ground. In the present estimates, shortwave absorption in the atmosphere is first scaled from pre-industrial via the top-of-the atmosphere insolation and in addition, the low-oxygen effect is approximated by a reduction (of the atmospheric 
shortwave absorption) by 10 and $5 \mathrm{~W} / \mathrm{m}^{2}$ for 4 and $1 \mathrm{Ga} B P$, respectively. The stratospheric temperature is assumed lower than contemporarily in the order of 100 and $59 \mathrm{~K}$ for the two times.

As result, the simple model of the present studies can well reflect the faint young Sun times, in accordance with energy budget considerations (see appendix Table 3 for details), if the planetary albedo was 0.13 in the Early Archean (4 Ba BP). At first sight, this appears far from reasonable. To examine this: As mentioned, the Early Archean exhibited high temperatures and near-complete oceanic coverage. Thus, the present tropic oceans may give guidance. Figure 3 shows measurement results for the present planetary albedo. For tropic oceans, 0.13 seem in the vicinity of the observed values.

In conclusion, it would come with no surprise if the faint young Sun problem were called resolved from sophisticated studies.

\section{Discussion}

It has been perceived challenging to extract the essentials on nature's processes from sophisticated research and to identify the topics relevant for the broader public. Also partly, there has been a missing link between qualitative explanations and quantitative reproducibility. The general idea is that such gaps may be filled by identifying the driving forces with help of simple models.

The present studies have focused on the planetary emittance as one of the fundamental regulators of Earth's climate. The inherent complexity of the underlying intertwined processes is reduced, first by decoupling planetary emittance from the longwave absorption in the low troposphere. Second, the emittance subdivision is chosen as radiation from clouds, from the (cloud-free) atmosphere, and through the atmospheric window. Third, observed information is used as input where bottom-up computation is too complex for simple modelling. Fourth, only few basic principles are applied.

The resulting simple model can well describe a wide range of climate situations, including doubling of the $\mathrm{CO}_{2}$ concentration and the faint young Sun; key criterion is that energy balance be established at all considered climate states. This model success is regarded as confirmation that the driving forces are correctly identified, particularly the water vapor and lapse rate temperature dependencies as well as the stratospheric temperature variations. The model setup is interpreted to well reflect on average the interplay of the diverse underlying processes.

The results on the natural variabilities in brief: Emittance altitude and temperature increase in line with surface temperature. - Lapse rate is an intrinsic feature closely tied to the surface temperature, hence not assigned to a separate role in planetary emittance. A surface temperature dependency of $0.05(\mathrm{~K} / \mathrm{km}) / \mathrm{K}$ appears as a realistic mean value. - In contrast, water vapor has an active role. The emittance from the ' $\mathrm{H}_{2} \mathrm{O}$ ' wavelengths in absolute terms, i.e. nearly $90 \%$ of atmospheric emittance, reveals strong sensibility to details of the tropospheric temperature profile. - The stratospheric temperature is inferred to exhibit vital adaptation at surface temperatures above $291 \mathrm{~K}$. - Emittance from $\mathrm{CO}_{2}$ is strongly influenced by stratospheric temperature variabilities. - The present model principally works for a range of cloud feedback 
parameters; $0.7 \mathrm{~W} / \mathrm{m}^{2} / \mathrm{K}$ is the preferred value in view of the sound results and the consistency with energy budget comparisons (based on accounting scheme as well as measurements). - For equilibrium upon $\mathrm{CO}_{2}$ concentration doubling from pre-industrial, the total feedback parameter is reigned by the contributions from the atmospheric window, the clouds, and albedo; radiation from the atmosphere delivers -0.36 $\mathrm{W} / \mathrm{m}^{2} / \mathrm{K}$, revealed as $\mathrm{CO}_{2}$-dominated with $80 \%$ (in relative terms between the two variability cases). - The present approach may point towards an explanation of the faint young Sun climates.

The hope is that provision of a simple model such as the present helps to filter the essential and to offer reproducibility and transparency.

\section{Declarations}

Supplementary Materials: All data and code are available: Simplified climate modelling.

Conflicts of Interest: No conflict of interest is to be declared.

\section{References}

1. Hanel R.A., Schlachman B., Rogers D., Vanous D. Nimbus 4 michelson interferometer. Applied optics 1971, $106,1376-82$.

2. Anderl T. 2021. Earth's balanced climates in view of their energy budgets. Preprint. https://www.researchsquare.com/article/rs-568771/v1. doi: 10.21203/rs.3.rs-568771/v1.

3. Flato G., Marotzke J., Abiodun B., Braconnot P., Chou S.C., Collins W., Cox P., Driouech F., Emori S., Eyring V., Forest C., Gleckler P., Guilyardi E., Jakob C., Kattsov V., Reason C., Rummukainen M. 2013: Evaluation of Climate Models. In: Climate Change 2013: The Physical Science Basis. Contribution of Working Group I to the Fifth Assessment Report of the Intergovernmental Panel on Climate Change [Stocker, T.F., D. Qin, G.-K. Plattner, M. Tignor, S.K. Allen, J. Boschung, A. Nauels, Y. Xia, V. Bex and P.M.

Midgley (eds.)]. Cambridge University Press, Cambridge, United Kingdom and New York, NY, USA, Figure 9.43, pp. 741-866, doi:10.1017/CB09781107415324.020.

4. Anderl T. 2021. The climate role of $\mathrm{CO}_{2}$ - nature's telling from 400 million years. Preprint. https://www.researchsquare.com/article/rs-524780/v1. doi: 10.21203/rs.3.rs-524780/v1.

5. CERES Science Team, NASA Langley Research Center in Hampton, Virginia, USA. https://ceres.larc.nasa.gov/images/best-of-ceres/alb_ann_180.png. Retrieved 06-03-2021.

6. Anderl T. 2021. The climate roles of $\mathrm{H}_{2} \mathrm{O}$ and $\mathrm{CO}_{2}$ from longwave absorption. In preparation.

\section{Appendix}

Re. planetary emittance, § 4.2.1 


\begin{tabular}{|c|c|c|c|c|c|c|c|c|}
\hline \multicolumn{9}{|c|}{$p \mathrm{CO}_{2}$ driving surface temperature } \\
\hline \multirow[t]{2}{*}{$\begin{array}{l}T_{\text {surface }} \\
(\mathrm{K})\end{array}$} & \multirow[t]{2}{*}{$\begin{array}{l}Q_{\text {surface }} \\
\left(W / m^{2}\right)\end{array}$} & \multirow[t]{2}{*}{$\begin{array}{l}p \mathrm{CO}_{2} \\
\text { (ppmv) }\end{array}$} & \multicolumn{3}{|c|}{ Emittance $\left(\mathrm{W} / \mathrm{m}^{2}\right)$} & \multicolumn{2}{|c|}{$\begin{array}{l}\text { Absorbed insolation } \\
\text { change }\left(\mathrm{W} / \mathrm{m}^{2}\right)\end{array}$} & \multirow{2}{*}{$\begin{array}{l}\text { Stratospheric } \\
\text { temperature } \\
\text { change }(\mathrm{K})\end{array}$} \\
\hline & & & $\begin{array}{l}\text { atmos- } \\
\text { phere }\end{array}$ & clouds & $\begin{array}{l}\text { atm. } \\
\text { window }\end{array}$ & glaciation & insolation & \\
\hline 284 & 368.9 & 176 & 168.2 & 33.5 & 37.3 & -2.1 & - & 0 \\
\hline 287 & 384.7 & 276 & 171.8 & 31.4 & 38.9 & 1 & - & 0 \\
\hline 291 & 406.6 & 500 & 173.5 & 28.6 & 41.1 & 2 & - & 0 \\
\hline 291.7 & 410.5 & 552 & 173.4 & 28.1 & 41.5 & 2 & - & -3.5 \\
\hline 296 & 435.3 & 1050 & 175.2 & 25.1 & 44.0 & 3 & - & -22 \\
\hline 297 & 441.2 & 1225 & 175.3 & 24.4 & 44.6 & 3 & - & -29 \\
\hline 306 & 497.1 & 3600 & 175.7 & 18.1 & 50.3 & 3 & - & -18 \\
\hline
\end{tabular}

Table 1. Planetary emittance for various climates, $\mathrm{CO}_{2}$ concentration driving temperature. Input values: surface temperature $T_{\text {surface; }}$ surface blackbody radiation $\mathrm{Q}_{\text {surface; }}$ atmospheric $\mathrm{CO}_{2}$ mixing ratio $p \mathrm{CO}_{2}$, related to $\mathrm{T}_{\text {surface }}$ according to the Eocene $\mathrm{CO}_{2}$-temperature relationship [4]; changes of absorbed insolation from glaciation-related albedo relative to implicit reference climate; stratospheric temperature relative to the present. Model results: emittance from the (cloud-free) atmosphere, from clouds and through the atmospheric window.

Re. planetary emittance, § 4.2.2

\begin{tabular}{|c|c|c|c|c|c|c|c|c|}
\hline \multicolumn{9}{|c|}{ Temperature driving $\mathrm{pCO}_{2}$} \\
\hline \multirow[t]{2}{*}{$\begin{array}{l}T_{\text {surface }} \\
(\mathrm{K})\end{array}$} & \multirow[t]{2}{*}{$\begin{array}{l}Q_{\text {surface }} \\
\left(W / m^{2}\right)\end{array}$} & \multirow[t]{2}{*}{$\begin{array}{l}p \mathrm{CO}_{2} \\
\text { (ppmv) }\end{array}$} & \multicolumn{3}{|c|}{ Emittance $\left(\mathrm{W} / \mathrm{m}^{2}\right)$} & \multicolumn{2}{|c|}{$\begin{array}{l}\text { Absorbed insolation } \\
\text { change }\left(\mathrm{W} / \mathrm{m}^{2}\right)\end{array}$} & \multirow{2}{*}{$\begin{array}{l}\text { Stratospheric } \\
\text { temperature } \\
\text { change }(K)\end{array}$} \\
\hline & & & $\begin{array}{l}\text { atmos- } \\
\text { phere }\end{array}$ & clouds & $\begin{array}{l}\text { atm. } \\
\text { window }\end{array}$ & glaciation & insolation & \\
\hline 278 & 338.7 & 100 & 156.4 & 37.7 & 34.2 & -13 & 0 & 0 \\
\hline 284 & 368.9 & 220 & 168.7 & 33.5 & 37.3 & -1.7 & 0 & 0 \\
\hline 287 & 384.7 & 280 & 171.8 & 31.4 & 38.9 & 1 & 0 & 0 \\
\hline 295 & 429.4 & 440 & 179.5 & 25.8 & 43.4 & 3 & 5 & 10 \\
\hline 305 & 490.7 & 640 & 190.2 & 18.8 & 49.6 & 3 & 15 & 30 \\
\hline 315 & 558.2 & 840 & 200.0 & 11.8 & 56.5 & 3 & 25 & 31 \\
\hline
\end{tabular}


Table 2. Planetary emittance analog to Table 1 , here temperature driving atmospheric $\mathrm{CO}_{2}$ concentration. Differences to Table 1: atmospheric $\mathrm{CO}_{2}$ mixing ratio $p \mathrm{CO}_{2}$ proportional to surface temperature with 20 $\mathrm{ppmv/K}$ [4]; changes of absorbed insolation from insolation change relative to pre-industrial.

Re. faint young Sun, § 4.2 .5 


\begin{tabular}{|c|c|c|c|}
\hline & Early Archean & Late Proterozoic & pre-industrial \\
\hline Time (Ga BP) & 4 & 1 & 0 \\
\hline \multicolumn{4}{|l|}{ General conditions } \\
\hline $\begin{array}{l}\text { Insolation }(\mathrm{SW}) \text { TOA }\left(\mathrm{W} / \mathrm{m}^{2}\right) \\
\text { re. pre-industrial }\end{array}$ & $\begin{array}{r}261 \\
-80\end{array}$ & $\begin{array}{r}321 \\
-20\end{array}$ & $\begin{array}{r}341 \\
-\end{array}$ \\
\hline $\begin{array}{l}\text { Temperature }(\mathrm{K}) \\
\text { surface } \\
\text { stratosphere re. pre-industrial }\end{array}$ & $\begin{array}{l}306 \\
-100\end{array}$ & $\begin{array}{l}306 \\
-59\end{array}$ & 287 \\
\hline $\begin{array}{l}p \mathrm{CO}_{2}(\mathrm{ppmv}) \\
\quad \text { factor re. pre-industrial }\end{array}$ & $\begin{array}{r}30,000 \\
107\end{array}$ & $\begin{array}{c}3,600 \\
13\end{array}$ & 276 \\
\hline $\begin{array}{l}\text { Low-oxygen effect }\left(\mathrm{W} / \mathrm{m}^{2}\right) \\
\text { shortwave absorption stratosphere }\end{array}$ & -10 & -5 & - \\
\hline $\begin{array}{l}\text { Continental coverage } \\
\text { continent, plus ice } \\
\text { ocean, plus ice }\end{array}$ & $\begin{array}{l}0.027,0 \\
0.973,0\end{array}$ & - & $\begin{array}{l}0.265,0.03 \\
0.685,0.02\end{array}$ \\
\hline $\begin{array}{l}\text { Temperature and continental coverage effect } \\
\text { planetary albedo }\end{array}$ & 0.13 & 0.27 & 0.3 \\
\hline \multicolumn{4}{|l|}{ Energy budget } \\
\hline SW reflection from albedo $\left(\mathrm{W} / \mathrm{m}^{2}\right)$ & 34 & 86 & 102 \\
\hline $\mathrm{SW}$ after albedo (absorbed insolation) $\left(\mathrm{W} / \mathrm{m}^{2}\right)$ & 227 & 235 & 239 \\
\hline Absorbed insolation re. pre-industrial $\left(\mathrm{W} / \mathrm{m}^{2}\right)$ & -12 & -4 & - \\
\hline LW atmosphere to surface $\left(\mathrm{W} / \mathrm{m}^{2}\right)$ & 424 & 434.5 & 333 \\
\hline $\begin{array}{l}\text { LW planetary emittance }\left(\mathrm{W} / \mathrm{m}^{2}\right) \\
\text { of this clouds } \\
\text { clear sky } \\
\text { atmospheric window }\end{array}$ & $\begin{array}{c}227 \\
18 \\
159 \\
50\end{array}$ & $\begin{array}{c}235 \\
21 \\
164 \\
50\end{array}$ & $\begin{array}{c}239 \\
30 \\
169 \\
40\end{array}$ \\
\hline Planetary emissivity & 0.457 & 0.473 & 0.602 \\
\hline \multicolumn{4}{|l|}{ Emittance - present model } \\
\hline $\begin{array}{l}\text { LW planetary emittance }\left(\mathrm{W} / \mathrm{m}^{2}\right) \\
\text { of this clouds } \\
\text { clear sky } \\
\text { atmospheric window } \\
\text { difference to energy budget }\end{array}$ & $\begin{array}{c}227 \\
18 \\
159 \\
50 \\
0\end{array}$ & $\begin{array}{l}235 \\
18 \\
167 \\
50 \\
0\end{array}$ & $\begin{array}{l}242 \\
31 \\
172 \\
39 \\
3\end{array}$ \\
\hline
\end{tabular}

Table 3. Key figures for planetary emittance estimates related to the Early Archean and Late Proterozoic with pre-industrial conditions as reference; SW for shortwave, LW for longwave, TOA for top of the atmosphere, $p \mathrm{CO}_{2}$ for atmospheric $\mathrm{CO}_{2}$ volume mixing ratio. Upper section: characteristic conditions; 
middle section: estimates from the energy budget (cf. [2]); lower section: estimates from the present simple model.

\section{Figures}
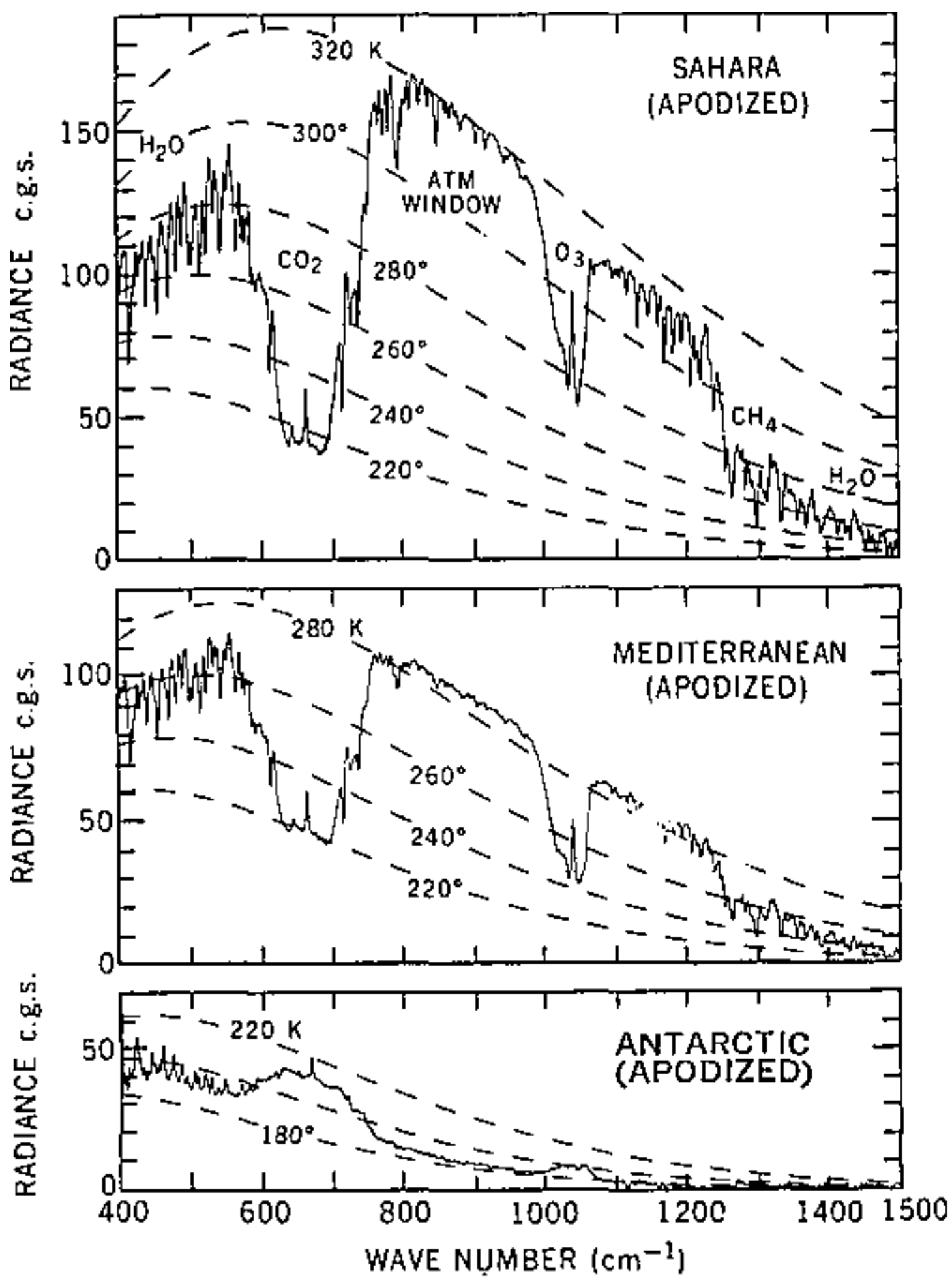

Figure 1 
Infrared emittance spectra for three cases, from top to bottom: hot desert, intermediate surface temperature over water, and extremely cold surface condition; blackbody radiances at several temperatures superimposed; from [1]

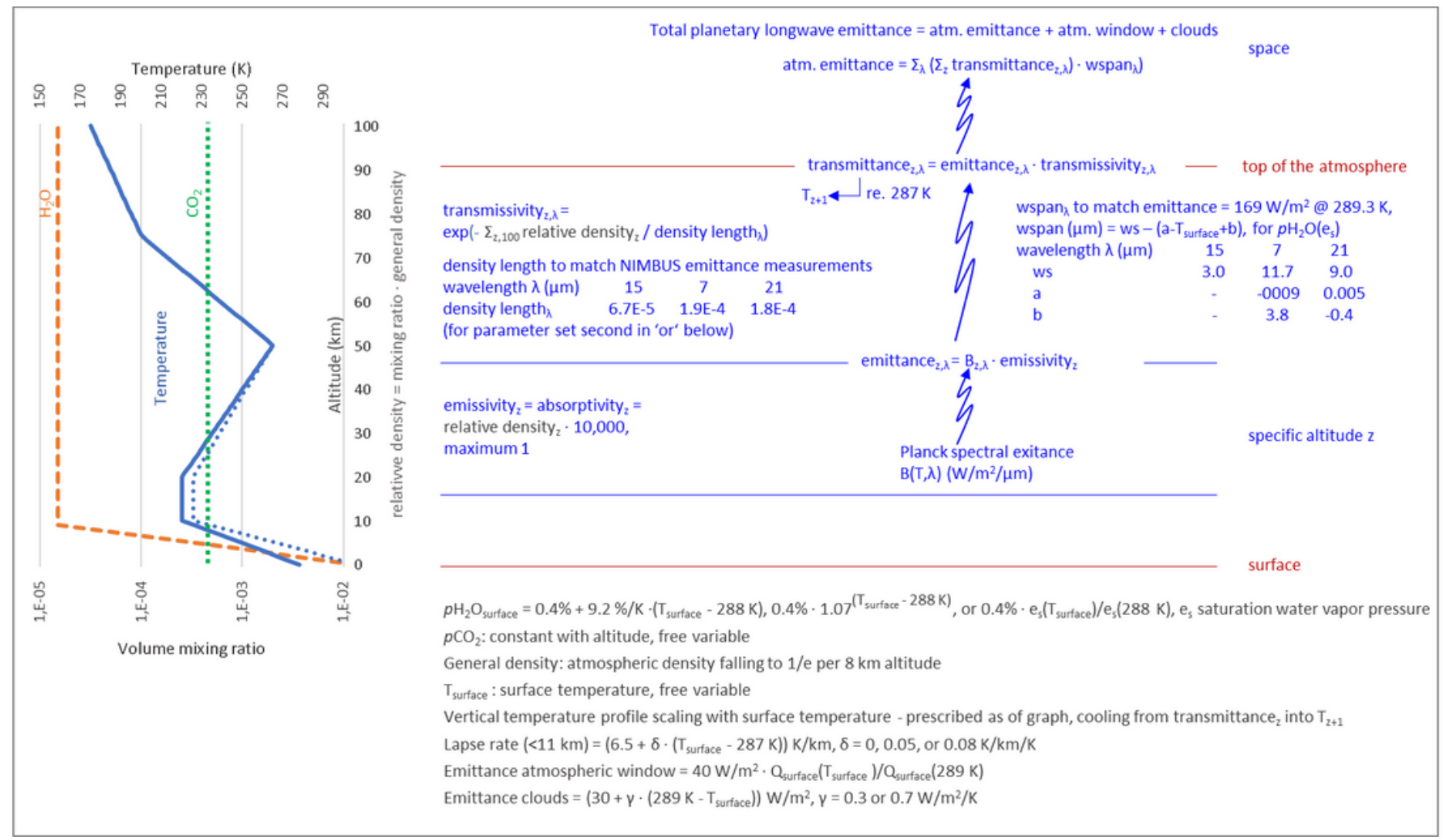

\section{Figure 2}

Depiction of the estimation scheme for atmospheric emittance to space via the vertical transmittance distribution, the longwave spectrum represented by the $\mathrm{CO} 2$ absorption band at $15 \mu \mathrm{m}$ and the adjacent H2O-dominated absorption regimes at 7 and $21 \mu \mathrm{m}$; graph insert showing the vertical patterns of temperature and volume mixing ratios for water vapor and $\mathrm{CO} 2$ at reference conditions related to $288 \mathrm{~K}$ surface temperature. 


\section{Shortwave Albedo 7/2005 - 6/2015}

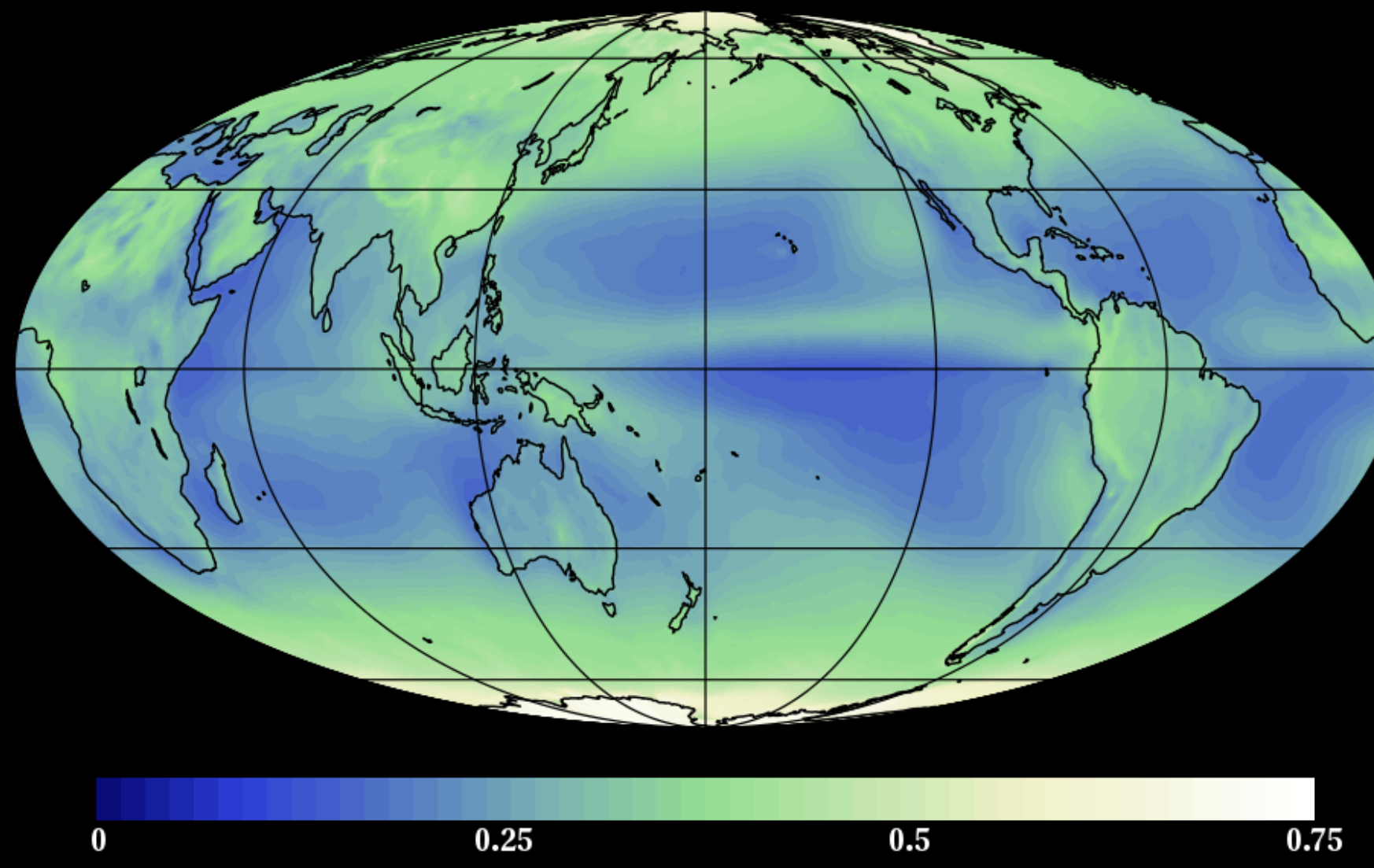

\section{Figure 3}

Measured annual top-of-the-atmosphere shortwave albedo; image courtesy of the CERES Science Team at NASA Langley Research Center in Hampton, Virginia, USA [5] 